\title{
Experiência, linguagem e narração: problemas teóricos e reflexões a partir de pesquisa de campo
}

\section{Guilherme F. W. Radomsky ${ }^{*}$}

\section{Resumo}

Recorrendo a uma variedade de escritos sobre experiência, linguagem, narração e processos de subjetivação, especialmente de Walter Benjamin, Michel Foucault e Giorgio Agamben, argumento neste artigo que, entre agricultores ecológicos do oeste de Santa Catarina, Brasil, o passado é constantemente acionado nas narrativas dos atores e o ato de visualizar um futuro desejado acontece por meio das experiências vividas, particularmente por momentos de introspecção e colaboração. Fundamentado em pesquisa de campo de caráter etnográfico, analiso como a relação passado-futuro na agroecologia problematiza os modelos de desenvolvimento rural, integrando e entrelaçando as experiências pessoais compartilhadas com narrativas e práticas, pois envolve memórias de sofrimento, exploração, desejos não realizados e, simultaneamente, trabalho em grupo com construção coletiva de ideais. Esse contexto empírico é particularmente propício para a reflexão sobre desenvolvimento, uma vez que este é entendido como um processo no qual aparecem tanto a superação das formas de exploração como a autoconstrução subjetiva e colaborativa.

Palavras-chave: experiência; narrativa; desenvolvimento; cooperação; agroecologia.

\footnotetext{
* Universidade Federal do Rio Grande do Sul, Porto Alegre, RS, Brasil.
} 


\section{Experience, language and storytelling: theoretical issues and fieldwork reflections}

\section{Abstract}

Drawing on a range of works about experience, language, storytelling and subjectivation processes, especially of Walter Benjamin, Michel Foucault and Giorgio Agamben, I argue in this article that among ecological smallholder farmers from West of Santa Catarina, Brazil, the past is constantly triggered in the actors' narratives and the act of visualizing a desired future happens through their lived experiences, particularly in moments of introspection and collaboration. Based on fieldwork data from ethnographic research, I analyze how the past-future relationship in agroecology challenges rural development models, integrating and interweaving shared experiences with narrative and practices, as it involves memories of suffering, exploitation, unfulfilled desires and, simultaneously, group work with collective construction of ideals. This empirical context is particularly useful for thinking about development, since it is understood as a process in which both the overcoming of forms of exploitation and subjective and collaborative self-construction emerge.

Keywords: experience, storytelling, development, cooperation, agroecology.

\section{Introdução ${ }^{1}$}

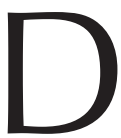

urante pesquisa realizada no oeste do estado de Santa Catarina, sul do Brasil, junto a agricultores e consumidores envolvidos com agroecologia, estive algumas vezes em Novo Horizonte, pequeno município localizado ao norte do mais populoso da região, Chapecó (lugar mais recorrente de minha pesquisa). Numa das ocasiões, havia ido especialmente para entrevistar técnicos mediadores e famílias agroecologistas e, em algum momento, convidaram-me para assistir uma peça de teatro.

Arnaldo, meu interlocutor no município, explicou que essa encenação amadora tinha a finalidade de representar a opressão pelas grandes empresas, a modernização na agropecuária, os riscos no uso dos agrotóxicos e a perda

$1 \mathrm{O}$ autor agradece aos(às) pareceristas de Sociologias pela leitura cuidadosa do trabalho bem como pelas sugestões dadas ao artigo. 
da biodiversidade na agricultura. Entusiasmado, olhando para frente como se antevisse o espetáculo, ele falou sobre a participação de estudantes no evento e da importância do momento. Mesmo não podendo comparecer, refleti sobre a dramatização e a aglutinação de energias que o teatro carrega para ritualizar e para intensificar determinado problema social.

Essa sensação transmitida por ele acerca de a pessoa olhar, refletir e também ser olhada por outros marcou-me por muitos motivos. O olhar que remete a si próprio conduz ao problema do sujeito que se constitui na volta que faz sobre si mesmo (Foucault, 2006, 2010). Sobre isso, Deleuze (2005) destacou a categoria de dobra e, comentando a obra de Foucault, percebeu que dos gregos aos cristãos tal história ampara um procedimento de constituição de interioridade de si peculiar ao pensamento ocidental. Essa capacidade de emergência do sujeito coloca-se num registro especular, o que implica novamente o tema do olhar.

À medida que narra os atributos simultaneamente lúdico e sério da encenação por vir, ouço meu interlocutor dizer, logo em seguida: "queremos um modelo diferente de desenvolvimento". Pergunto-me, então: o que ocorreria se as coisas encenadas fossem o vivido ou a forma que se quer dar à vida? Em seguida, estabeleço as ligações entre uma e outra frase dele e recordo que, em algum momento anterior, meu entrevistado enfatizara a noção de cooperação. Uma das propriedades que assume esse modelo distinto é o aspecto cooperativo que se pretende ressaltar, comentou; não basta uma produção ecológica, pois esta deve ser inclusiva socialmente - e ele segue falando e destacando que, no ato de desejar fazer algo diferente, a cooperação precisa estar presente em todos os momentos.

Entretanto, se a performance teatral e o discorrer livremente acerca do mundo das relações econômicas conduzem a um tipo de iluminação crítica, o que insinuam em termos propositivos? Fato comum em pesquisa de campo de longa duração consiste em nossos interlocutores nos direcionarem ao que querem falar - preferível à imposição de uma problemática sociológica a eles. Por esse motivo a trama de problemas me levou a refletir com eles sobre cooperação, autonomia e desenvolvimento, ainda que eu não tenha 
propósitos de fazer exame exaustivo disso. O foco da análise está em uma investigação sobre experiência, linguagem e narração, desdobrando-se em questões que circundam subjetividade, memória, sentimento de exploração e sofrimento. Este será, assim, o percurso e o objetivo do texto que, no princípio, apresentará problemas teóricos sobre o conceito de experiência e, após, alguns caminhos da pesquisa de campo que me guiaram a tentar compreender o modo como os atores falam de seu mundo vivido, das reminiscências, do coletivo e do individual.

Ressalto que o texto não tem por objetivo central expor o que seja agroecologia, tampouco como funciona a certificação de produtos, temas já abordados por autoras e autores. As ocasiões na pesquisa de campo conexas à agroecologia se voltam a problemas do cotidiano dos atores, como antes exposto. Mas, para fins de entendimento, procuro precisar em que bases conceituais agroecologia pode ser definida e particularmente diferenciada de agricultura orgânica.

Procedo no sentido de mostrar que algumas das experiências vividas pelos agricultores são potencializadas por momentos de estarem juntos, colaborarem e sentirem a vida à sua volta. Experiências são formadas aos poucos e, com elas, surgiam situações que me faziam entender a apropriação do mundo. Essas experiências estão sempre, procuro descrever, articuladas à passagem do tempo, tanto em dimensões de avaliação emotiva a respeito do que fizeram seus antepassados como nos sonhos que imaginam o futuro.

Havia a possibilidade de explorar o tema da subjetivação conexo à moralidade de comportamentos relacionados à autoprescrição de normas de conformidade de orgânicos nos sistemas de garantia participativos. Todavia, o rumo da argumentação se voltaria em direção ao dilema entre ditames externos e práticas de imposição de regras próprias. A opção foi destacar de que modo experiências e memórias se entrelaçam conjuntamente com os processos de reflexão e práticas que evocam transformações individuais e familiares, tal como num despertar para novas modalidades de pensar suas vidas. E é, ao final do texto, com a questão de qual concepção de desenvolvimento parece condizente com os anseios dos atores, que busco 
conectar o tema do desenvolvimento ao que recorrentemente escutei em campo: livrar-se de formas de exploração e buscar a autoconstrução coletiva e colaborativa.

Apresento neste artigo resultados de pesquisa realizada entre 2008 e 2009 no oeste de Santa Catarina, Brasil. Alguns dos tópicos discutidos apareceram parcialmente em Radomsky (2015). Para este texto, retornei ao diário de campo e às entrevistas, procurando enriquecer aspectos, organizar os pontos de vista e ampliar análises. À época, percorri diferentes municípios ao redor de (e incluindo) Chapecó, acompanhando agricultores, mediadores e consumidores urbanos envolvidos com agricultura ecológica em diferentes momentos - inserção de pesquisa que busco descrever mais adiante. Fiz observações em reuniões, feiras, locais de entrega de produtos, órgãos de assessoria política do setor e em outros espaços, além de entrevistas com variados atores que se relacionavam a esse mundo. Inicio a análise problematizando discussões teóricas e passo a momentos em campo que forneceram elementos indicativos de como a colaboração organizava práticas, para depois discutir as narrativas do passado simbolizado enquanto sofrimento e sua superação. Desenvolvimento e seus dilemas aparecem nas partes finais, nas quais procuro retomar aspectos antes discutidos, ressaltando as dimensões reflexivas e constitutivas dos sujeitos.

\section{O problema da experiência}

Aos leitores de Walter Benjamin que enfrentaram seus textos da juventude sobre experiência é um tanto desconcertante que, em 1940, poucos meses antes de morrer, ao escrever uma carta a Adorno ele confesse (Carta de 07 de maio de 1940):

Por que lhe esconder que as raízes da minha "teoria da experiência" remontam a uma recordação de infância? Meus pais saíam para passear conosco, como é natural, onde quer que passássemos a temporada de verão. Nós os irmãos éramos dois ou três [...]. Após termos visitado uma ou outra das atrações obrigatórias de Freudenstadt, Wengen ou de Schreiberhau, meu irmão 
costumava dizer: "Que lá estivemos, isso estivemos". A expressão imprimiuse indelevelmente em mim. (Adorno; Benjamin, 2012, p. 457).

Alguns dos textos da juventude são de grande complexidade (por exemplo, Benjamin, 1989a) e aqui o vemos recuperar momentos do vivido que são tocantes. Provavelmente, Adorno (1988) tinha isso em mente quando escreveu que Benjamin dava importância metodológica ao fragmento que - justamente por ser incompleto e fraturado - retém uma força que esvanece nos projetos universais. Nas Passagens, Benjamin deixa isso claro ao anotar o valor de "descobrir na análise do pequeno momento individual o cristal do acontecimento total" (Benjamin, 2009, p. 503).

Um dos debates frutíferos em torno da experiência se deu sobre a conceituação dada em alemão e que pode indicar sentidos muito diferentes quando se consideram as palavras Erlebnis e Erfarhung, ambas podendo ser traduzidas por experiência. Esse problema não decorre unicamente dos escritos de Benjamin, mas em outros que são participantes neste debate, tais como Dilthey, eventualmente numa posição de polarização. Na literatura recente, uma das exposições que abordam o ponto com clareza é a de Jay (2005). Erlebnis contém a raiz de vida (Leben, em alemão) e se traduz, muitas vezes, como "experiência vivida". Parte do mundo da vida cotidiana, podendo também referir a uma ruptura na vida rotineira. "Ainda que Leben sugira a totalidade da vida, Erlebnis geralmente conota uma variante mais imediata, pré-reflexiva e pessoal de experiência do que Erfarhung" (Jay, 2005, p. 11, trad. do autor).

Erfarhung faz referência a aspectos que podem se situar no nível do sensível, mas também "veio a significar uma noção temporalmente mais longa de experiência baseada em um processo de aprendizado, uma integração de momentos discretos de experiência em uma narrativa global ou aventura" (Jay, 2005, p. 11). Dá um sentido progressivo, de movimento no tempo, que se relaciona tanto a radicais que sinalizam "jornada" como "perigo" (também em Dawsey, 2013). Com Erfarhung, processam-se correlações entre memória, sabedoria e experiência acumulada e, vale dizer, todas 
se organizam por meio da linguagem. Por tais razões, costuma-se associar Erlebnis à experiência individual e Erfarhung à coletiva, mas, recorda Jay (2005), nem sempre é o caso.

Em Dilthey, o termo filosófico é Erlebnis e remete, então, à vivência interior do indivíduo. Foi Victor Turner quem deu atenção à discussão e mostrou que a noção de experiência de extração em Dilthey teria potencial relevante para o que ele denominou de antropologia da experiência (1985, 1986). ${ }^{2}$ Chama a atenção que aquilo que detém Turner no conceito de Erlebnis é o aspecto disruptivo de determinadas experiências, ou seja, o que é marcante para cada um de nós e não se confunde com o passar da vida cotidiana (também em Bruner, 1986). Esse aspecto inusual corrobora o que comentou Jay (2005) sobre Erlebnis e também reforça o caráter de Erfarhung estar mais próximo à mera experiência, daí o aspecto de acúmulo processual no tempo. Mas é possível pensar, como sugere Gagnebin (1985), que a importância que assume o termo Erlebnis seria fruto de uma sociedade voltada paulatinamente ao mundo individual, solitário e privado? Talvez esse seja um sintoma do que Benjamin afirmou: "as experiências estão deixando de ser comunicáveis" (1985a, p. 200). Agamben (2005) seguiu linha de argumentação próxima, já que examinou brevemente como Dilthey concedeu primazia à experiência interna como sendo aquela mais autêntica (cabe destacar, ao contrário do que Kant teria tentado argumentar acerca da sua impossibilidade de valor cognitivo). Para o filósofo italiano, Dilthey tentou "capturar esta experiência vivida tal como se revela à introspecção na sua imediatez preconceitual" (Agamben, 2005, p. 46).

Agamben (2012) também notou que se poderia extrair do grego e do latim algumas lições etimológicas sobre a matéria. O autor italiano liga a palavra grega empeiría - experiência - com atravessar, ir através, passagem,

2 Tema que não será detalhado aqui e que remete à antropologia do drama. Para Dawsey (2013), o debate proposto por Turner para uma antropologia da experiência ganharia ao incorporar a noção de Erfarhung. De qualquer modo, Dawsey parece entender que Erlebnis pode evocar uma imagem mais pobre e individualizada do vivido. Tanto Turner (1986) como Dawsey (2013) examinaram as propriedades das línguas inglesa e alemã para compreensão do conceito de experiência. 
porta e limite. A palavra latina experientia delimita um conteúdo semelhante, referindo-se à ideia de "ir através da ação na ação" (Agamben, 2012, p. 124). Citando a Metafísica de Aristóteles, Agamben sustenta a relação entre experiência e práxis: "Que apenas o homem seja capaz de experiência significa, por conseguinte, que apenas o homem determina a sua ação, isto é, a atravessa, e é, portanto, capaz de [práxis], do ir através até o limite da ação [...]" (Agamben, 2012, p. 125, itálico original).

Em Benjamin, o problema mais recorrentemente rememorado pelos comentadores no tocante à experiência é o da narração, ${ }^{3}$ tal como tematizado pelo autor (Benjamin, 1985a, 1985b). Porém, num dos escritos sobre Baudelaire, Benjamin recorre de maneira mais enfática ao papel da memória (igualmente discutida junto ao esquecimento nos textos sobre Kafka e Proust) ao afirmar que "[o]nde há experiência no sentido estrito do termo, entram em conjunção, na memória, certos conteúdos do passado individual com outros do passado coletivo" (Benjamin, 1989b, p. 107). Experiência, assim, nunca ocorre num vazio social, fazendo sentido a preponderância da narração, articulada à linguagem, e sua perda contemporânea quanto à capacidade para transmitir. ${ }^{4} \mathrm{~A}$ narração não se resume a passar uma informação, integra o dado narrado com a vida do narrador para transmitir aos ouvintes a própria experiência e "nela ficam impressas as marcas do narrador como os vestígios das mãos do oleiro no vaso de argila" (Benjamin, 1989b, p. 107). Tal dimensão do vivido na narração é retomada por Agamben no que se refere ao mundo crescentemente guiado pela ciência, pois daí decorre que são os instrumentos que fazem experiência (ou experimentos)

3 É preciso mencionar, devido à importância com relação à linguagem e às dimensões que não perpassam a filosofia da consciência, o pequeno texto de Benjamin (1999) sobre a faculdade mimética. É um dos fragmentos em que aparece claramente a importância dos aspectos sensoriais e perceptivos para experiência.

${ }^{4}$ Por essa razão, o sentimento, para o autor alemão, de que o novo tempo exigiria modos inovadores de transmitir experiência, tal como Dawsey (2013) recorda: o Surrealismo, o teatro de Brecht, a arte de Klee, a literatura de Kafka. Uma questão em jogo é a experiência do choque na modernidade, a relevância da imagem e das novas tecnologias e não mais uma retomada de um mundo da tradição. O dilema é até que ponto elas reconfiguram a experiência, permitem algum tipo de narratividade ou, inversamente, aprofundam o individualismo, como Kang (2009) sugeriu sobre o surrealismo. 
e apontam verdades. Recuperando Montagne, para Agamben a experiência seria o inverso da certeza. "Não se pode formular uma máxima nem contar uma estória lá onde vigora uma lei científica" (Agamben, 2005, p. 26).

Recuperemos outra vez o problema da linguagem, umbilicalmente ligado à capacidade de narrar. Leitor de Benjamin, Agamben (2005) avança nos argumentos para sustentar que se a linguagem é o lugar da experiência é porque não se pode assumir posição de sujeito sem ela: "[...] vemos então que é na linguagem que o sujeito tem sua origem e seu lugar próprio, e que apenas na linguagem e através da linguagem é possível configurar a apercepção transcendental como um 'eu penso'" (Agamben, 2005, p. 55-56).

Ocorre na filosofia de Agamben não aquela imagem da humanidade que simplesmente se faz enquanto espécie na linguagem. A linguagem está permanentemente separada de nós, não nascemos com ela; ao contrário, fazemo-nos a partir dela: "[s]omente porque existe uma infância do homem, somente porque a linguagem não se identifica com o humano e há uma diferença entre língua e discurso, [...] somente por isto existe história [...]" (Agamben, 2005, p. 64). E, num dos livros recentes, o autor italiano recupera o argumento da fratura entre os humanos e língua para afirmar:

O evento antropogênico coincide, portanto, com a fratura entre vida e língua, entre o vivente e o falante; mas, justo por isso, o tornar-se humano do homem implica a experiência incessante dessa divisão e, ao mesmo tempo, da igualmente incessante e nova rearticulação histórica do que foi dividido desse modo. O mistério do homem não é aquele, metafísico, da conjunção entre o ser vivo e a linguagem (ou a razão, ou a alma), mas aquele, prático e político, de sua separação (Agamben, 2017, p. 234).

A diferença entre língua e discurso, que permite ação histórica humana, é uma interpretação agambeniana certamente oriunda do legado de Benjamin (2011), quando este escreveu que a linguagem condiciona a comunicação de uma comunicabilidade. Na bela análise de Agamben (2017), isso é a própria potência de ser (e não ser) da linguagem, a potência de passar ao ato. 
Esse quadro interpretativo coloca a experiência em relação ao tempo e à ação, a aspectos sensoriais, perceptivos, e organizada pela linguagem portanto, indispensável que seja tarefa a ser realizada por sujeitos concretos e em sociedade. Situada a partir do acúmulo da tradição, somente desse ponto de vista se entende os conteúdos de memória que fornecem condições de concretização e sentidos para os modos como o futuro é desenhado.

\section{Ver, sentir, colaborar}

Em campo, parte do meu esforço era imaginar o que meu interlocutor antes mencionado contava que ocorreria no teatro; mas ainda não havia sucedido a encenação, então, eu também imaginava sua imaginação pela narração projetiva. É claro que isso difere do próprio teatro, porém faz um passeio curioso pelo sentimento tipificado no "quem encontra ainda pessoas que saibam contar histórias como elas devem ser contadas"? recordado por Benjamin (1985b, p.114). Curioso porque a narrativa projetava uma paisagem em que os olhares alternavam para o passado e para um mundo futuro. Sobre isso, John Dawsey considera que

[...] performances rituais e estéticas provocam mais do que um simples espelhamento do real. Instaura-se, nesses momentos, um modo subjuntivo ("como se") de situar-se em relação ao mundo, provocando fissuras, iluminando as dimensões de ficção do real - $f(r)$ iccionando-o, poder-se-ia dizer [...] (Dawsey, 2006, p. 136).

A representação teatral se vale do que ocorreu, ao mesmo tempo em que coloca parênteses nisto para, através da analogia e da metáfora, sensibilizar e inventar. $\mathrm{O}$ passado era aquele apropriado no momento da encenação, aquele que se desejava deixar para trás. Um mundo futuro não é único e dado, mas justamente "algum" que se espera ser melhor. O "lugar olhado das coisas", como Dawsey descreve em diferentes artigos (2006, 2009), é crucial para o entendimento da potencialidade do palco. Nessa relação, envolver o público e tornar esse momento explosivo, como num lampejo, supõe colocar a realidade num "como se não fosse do modo que 
é" e criar outra através da imaginação - a potência da linguagem narrativa. Apesar de cada impressão ser particular, eu via a importância de entender a dimensão social dessa apropriação.

Entre os agricultores ecológicos da região, todos envolvidos na Rede Ecovida de Agroecologia, o aspecto colaborativo do trabalho não era somente relevante em razão do fortalecimento dos grupos nos municípios e do acesso a mercados, mas também porque possibilitava construções de um modo de viver e de conhecer. Aprendi isso acompanhando os grupos em reuniões.

Antes de estar presente em reuniões, a inserção enquanto pesquisador se deu gradativamente e iniciou por conhecer agricultores e agricultoras na principal associação local de assessoria técnica e também nas feiras. Enquanto na associação os diálogos me permitiam ser mais objetivo e me aproximar do que eu aos poucos percebia ser importante no mundo deles, nas feiras as conversas eram intercaladas com observações e os laços diretamente constituídos com as famílias rurais abriam espaço para futuras relações de confiança. À medida que se fazia possível expor a elas minhas intenções pude sugerir participar das reuniões em grupo, ir às propriedades rurais para visitas mais extensas e até mesmo ser convidado para outras situações não antevistas por mim até aquele momento (eventos temáticos, reuniões regionais sobre certificação e visitas a agricultores da região que ainda não havia conhecido).

Diversos municípios do oeste catarinense possuíam iniciativas no âmbito da Ecovida, o que dinamizou a pesquisa e a melhor compreensão dessa territorialidade. Região caracterizada por agricultura familiar que passou por processos de modernização do campo e integração a agroindústrias, as experiências em agricultura ecológica se disseminavam, mesmo com dificuldades para adesões massivas.

Destaco que, durante a pesquisa de campo, agricultores e técnicos se referiam às suas práticas nomeando-as tanto por agroecologia como por agricultura ecológica (e nunca por orgânica). Em alguns casos, isso não expressava desconhecimento ou pouco rigor, pois se tratava de posição política. Uma agricultora e presidente de associação falou, certa 
vez, a mim que era agroecologista, destacando com ênfase o termo e desdenhando outras denominações, classificações impostas por outros. Contudo, a literatura científica diferencia o que sejam os orgânicos e o que se nomeia de agroecologia, ${ }^{5}$ ainda que trabalhos também apontem que o posicionamento de atores em campo corrompe as definições acadêmicas em favor de conceituações locais (Goodman; Goodman, 2007).

Cabe destacar que a Rede Ecovida foi fundada no sul do Brasil no fim dos anos 1990 e nasce dos movimentos ambientalistas e das experiências de organizações ou feiras já em curso em outros lugares. Era uma época em que, paulatinamente, o debate sobre alimentos, agricultura e sustentabilidade se tornava mais denso no Brasil e se destacaria nacionalmente alguns anos depois com a aprovação de leis e regulamentações normativas tanto para produção de orgânicos como para os sistemas de certificações.

Completando dez anos durante minha pesquisa, a Ecovida já possuía mais de vinte núcleos no sul do país, com sistema participativo de garantia, normas para famílias participarem, modelos de funcionamento locais e regional, selo reconhecido e formatos organizados de inclusão (e também de penalização) de membros. Além de rede formalmente constituída, "[...] através de uma nova compreensão da natureza, da construção de uma nova sociabilidade, da consideração do saber popular, do acúmulo de experiências, é que se constituía sua Identidade de Projeto" (Silveira, 2013). ${ }^{6}$

Numa das primeiras vezes em que estive entrevistando um agrônomo e dois agricultores na sede de uma associação em Chapecó fui instigado a ver que tais experiências em agroecologia não brotam "do nada". É

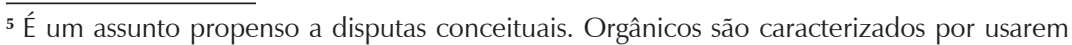
“um mínimo de insumos externos, evita[rem] os medicamentos veterinários, os fertilizantes (adubos químicos) e os pesticidas (agrotóxicos) de síntese" (Fonseca, 2005, p. 31). Há os apelos de agroecologia enquanto ciência, mas de modo geral o qualificativo ecológico é mais amplo que o de orgânicos e envolve dimensões sociais e éticas junto às ambientais. Mantive as diferentes expressões quando se mostraram adequadas. Para um panorama do debate, ver Assis e Romeiro (2002).

${ }^{6}$ O leitor encontrará variados documentos e trabalhos sobre a Rede, tais como Rover (2011) e Lucion (2016). Sobre o tema da agroecologia no sul do Brasil, incluindo também a Ecovida, ver a coletânea de Niederle et al. (2013). Sobre dificuldades de consolidação da Ecovida, ver Silveira (2013). 
preciso um trabalho de agremiações tanto para conversão como para manutenção dos grupos. Esta é, de certo modo, a história da Ecovida: trabalho e empenho de associações e famílias agricultoras que coletivamente se tornam fortalecidos e, assim, influenciam positivamente - eventualmente com auxílio técnico - a inserção de novos participantes locais e a criação de outros núcleos municipais em regiões próximas. Mesmo assim, ao longo dessa conversa, ficou claro que para muitos agricultores tais formatos sustentáveis de produção "fazem sentido", enquanto para outros não. Isso manifesta algo mais que apenas existirem assessoria técnica e mercados consumidores locais, pois se observa que algo ocorre no íntimo das pessoas numa espécie de ponte entre o passado e o presente vivido por cada um. Escreve Turner (1986, p. 33) que "significados emergem quando nós tentamos colocar o que a cultura e a linguagem cristalizaram do passado junto com o que sentimos, desejamos e pensamos sobre nosso momento de vida presente" (trad. do autor). Esses significados poderiam ser aliados a um trabalho de conversão, que não deve ser entendido como uma espécie de convencimento insistente, mas enquanto esforço coletivo para ampliar os grupos e a produção ecológica na região.

Um caso específico pode elucidar. Um dos meus interlocutores de Chapecó narrou que se engajou na agroecologia quando sua irmã cursou pósgraduação na área. Dessa trajetória individual provinha um grande incentivo de mudança para a família. Antes, vendia aves para uma grande empresa e a situação de intenso trabalho ("a exploração era grande", comentou) com pouca terra e rendimentos mais baixos do que esperavam despertou um sentimento de que precisariam investir e trabalhar cada vez mais para continuar com ganhos modestos. Essa situação foi o estopim da mudança. Enquanto relatava, recordo de haver pensado em instrumentalismo de sua parte, contudo, completou que, tendo recebido a terra dos antepassados e vendo a deterioração ambiental, desistiram dessa produção e focaram os investimentos na agricultura ecológica.

Nas reuniões regulares realizadas nas casas dos agricultores, nas quais recebiam seus pares e alguns técnicos ou interessados, a dinâmica obedecia 
em geral a uma circularidade "palavra-movimento-palavra". Começava-se com uma conversa mais aberta até todos estarem presentes, quando se comentavam amenidades ou assuntos candentes da política. O momento seguinte era crucial: caminhar pelos cultivos e criações, ver a paisagem e sentir o terreno. $\mathrm{O}$ anfitrião convidava todos para andar pelas áreas e as conversas continuavam, mas a visualidade do processo importava. Nas reuniões, todos, exceto eu, sabiam bem o que enxergavam. Eu aprendia com dificuldade, mas era claro que não fazia parte do grupo, pois não trazia incorporado aquele saber acumulado.

Nesse passeio avaliativo, agricultores e agricultoras conversam sobre os modos de trabalho; trocam ideias sobre preparação de alimentos, usos para alimentação animal e mesmo sobre mercados para certos produtos. Quero destacar que o grupo presente demonstra habilidades e sabe multiplicar as possibilidades de usos dos cultivos, cada um dando uma opinião ligeiramente distinta. Essas caminhadas evocavam movimento, ação e percepção da paisagem: era crucial que a apresentação dos cultivos não permanecesse somente enquanto relato do dono da terra e que todo o grupo pudesse se deslocar, ver, sentir o solo e perceber o terreno.

Havia ritualização e periodicidade desses momentos. A terceira parte do evento usualmente consistia em sentarem-se para nova conversa, porém voltada ao que havia sido visto na área visitada. Apareciam avaliações e perspectivas, pequenos conflitos e até certa "chamada de atenção", dependendo do caso (se a produção apresentava algum problema ou se algo poderia ferir as normas). O que vale destacar também é a forma como um entendimento tácito se realizava, sendo que, para os agricultores, aquele momento é de aprendizado, exposição de conhecimentos, troca de informações, escuta de opiniões e críticas.

Quando as reuniões eram em associações ou outras agremiações, esse momento de prática e movimento não ocorria. É claro que, em todas as situações, a exposição pelas pessoas de seus sucessos e insucessos, ganhos e frustrações, era relevante e - inclusive nas entrevistas individuais - a dimensão da narração tinha fôlego. 
Nas variadas situações em que estive presente e que envolveram colaboração - proposta de constituição de bancos de sementes, ${ }^{7}$ parcerias com entidades públicas, troca de conhecimentos sobre cultivares - essa associação entre uma prática que se aglutina com o modo de se referir verbalmente a ela foi definidora. Era sensibilizador entender que a disseminação de ideias e práticas também tinha um movimento, ela se espalhava em distintas direções (como se multiplicam as experiências em agroecologia) gerando adaptações e diferenciações e oportunizando novas narrativas sobre o que cada um vivia em suas terras e em família.

\section{A experiência da exploração e do sofrimento}

Ao longo da pesquisa encontrei pessoas dispostas a relatar sofrimentos pelos quais passaram durante a vida trabalhando na agricultura. Nos diálogos, as experiências apareciam em relação a um passado recuperado e narrado constantemente nos relatos. Por isso, as memórias familiares ou comunitárias eram confrontadas com o panorama possível de inserção dos sujeitos. Tal como escreveu Turner (1985), nossos códigos culturais e de comunicação estão saturados das experiências pregressas dos nossos antepassados, mas podem nunca se tornarem experimentadas por nós sem que sejam performadas.

Os atores haviam feito uma conversão para agricultura ecológica, como costumam se referir, e isso thes fez abrir os olhos para o que viviam até então. Assim, era comum que contassem sobre eles próprios, antes, terem utilizado venenos na produção, e também sentido o sofrimento dos outros, especialmente das gerações anteriores com as quais se identificavam. Aquele passado, que para muitos não queria passar, criava uma tônica de

7 Iniciativa que tinha por meta a autonomia das famílias para manutenção in situ de sementes, contou com apoio de organizações com presença regional. Permitia igualmente que a diversidade genética circulasse na região. Uma exemplificação etnográfica do extremo sul do Brasil - e da relação com os transgênicos - pode ser encontrada em Benvegnú e Radomsky (2020). 
dor, porém, simultaneamente, viam futuro com a agroecologia e com as atividades colaborativas nela implicadas.

Benjamin expõe numa passagem que "para que um fragmento do passado seja tocado pela atualidade não pode haver qualquer continuidade entre eles" (Benjamin, 2009, p. 512). É no momento presente que se estabelecem as constelações entre o agora e o antes, e no contexto eu percebia o intervalo entre o que a modernização agrícola orquestrou projetos de intervenção em nome do desenvolvimento significativamente orientados para o uso de toda a sorte de artifícios tecnológicos - e o que a conversão à agroecologia produz na vida das pessoas. $\mathrm{O}$ toque supõe também um despertar, ademais, funciona como um relembrar específico - da agricultura dita "natural", da tradição de antes da modernização, certamente idealizada nas rememorações e com potencial gigantesco de transformação hoje. Esse despertar evocava a insistência dos indivíduos em rememorar o passado coletivo de gerações de agricultores que viveram condições difíceis.

Laudemar, agricultor do município de Seara, próximo a Chapecó, contou com sensibilidade como havia se tornado agroecologista. Após confirmar que a Rede atua na disseminação da "mensagem", na qual núcleos mais antigos e organizações da sociedade civil atuam em conjunto para formar outros grupos em diferentes regiões, narrou sobre as imagens que o estimularam. Novamente, é o olhar reflexivo que potencializa a ação, pois foi através de curso de formação que teve acesso de fato às consequências da história da agricultura modernizada e seus efeitos perversos. "Foi uma coisa que me despertou, tanto a história da migração, dos que erodiram a terra, migraram para Santa Catarina, depois para Mato Grosso e etc., como das imagens [fotos, vídeos] de doenças ligadas aos venenos". Essa genealogia emociona, uma vez que o sentimento também está em partilhar as trajetórias e ver-se sensibilizado pelos relatos.

Já de meia idade na época, recordando a dificuldade em trabalhar na dependência de grandes empresas do setor agroindustrial, refletiu também sobre o caráter coletivo da agricultura ecológica: 
eu não voltaria a trabalhar com suínos, porque [a riqueza] fica cada vez mais nas mãos de poucos. Fica nas mãos dos que crescem e acabam com os concorrentes, e principalmente nos frigoríficos. A suinocultura é muito forte na região, as pessoas já têm a tradição de produzir suínos, frangos, grãos. Então para elas é difícil mudar.

Chama a atenção que o agricultor cogita sobre o sofrimento do outro, portanto, aprender na agroecologia combina o olhar introspectivo com a visualização dos problemas por que passam os pares - olhar e ser olhado - e o quanto impactam as narrativas de sofrimento ou a sensação de medo de abandonar o que é economicamente seguro.

Em visita a outra família do município de Novo Horizonte, com que tive a oportunidade de partilhar momentos, tentei sentir o quanto estar em dependência de grandes empresas para viver pode ser árduo. Destaca-se que os contratos com as corporações costumam depositar os riscos sobre os agricultores e, ainda que possa haver seguro contra perda de safras, a dinâmica do tempo, o uso da força de trabalho da família e a relação com as intempéries, muitas vezes, é de foro doméstico, importando a produção no final do ciclo. Comentaram com ênfase sobre qual sentido haveria em se plantar monoculturas e quase não ter espaço para produzir alimentos para a própria família. Atestando tal amargura, um dos filhos sustentou que haviam sido "escravos" - nos seus termos - da indústria do tabaco e viveram a situação de obrigarem-se a comprar comida durante anos, mesmo tendo terra. Era como se houvesse uma falsidade em viver no campo dessa maneira e a justaposição no relato entre trabalho e "escravos" gerava um assombro: "isso [o que viveram nesse período] não é ser agricultor", falou o filho mais velho. Embora possa nos direcionar a pensar que há uma essência do camponês, realmente faz sentido entender a resistência posta em prática por eles para evitar o sofrimento. Mas é fundamental entender esta unicidade da experiência para a família: conforme Hartmann (2005), citando Bruner (1986), nós criamos unidades de experiência da usual continuidade - do fluxo - da vida. Quando começa e termina certa 
experiência é algo como uma imposição arbitrária de significado no fluxo dos acontecimentos.

Perceber descontinuidade dos acontecimentos no tempo é parte da experiência e coloca também a realidade no subjuntivo, como Dawsey (2006) sublinha. Mas aqui emerge o que poderia ter sido o futuro sem deixar a dependência e, especialmente, outro dilema, o de estar num lugar olhado pelos outros. "Vocês vão voltar ao passado?", ouviam dos vizinhos, contou-me a mesma família antes mencionada. Escutavam essa indagação um tanto raivosa quando pararam de usar agrotóxicos fazendo a opção pela agroecologia. Coloca-nos a questão de que, no momento em que alguém passa a fazer parte de uma espécie de "outro", diferente (o ecológico que não segue as receitas tecnológicas usuais de modernização), é a concepção de tempo (atrasado ou moderno) que define as classificações sociais.

\section{Reflexão: o desenvolvimento em questão}

O ato de sonhar pode ter efeito desestabilizador quando recorda o que não foi realizado e permanece reprimido. Sonhar pode desmascarar a ruína do que não foi concretizado. Na leitura instigante de Buck-Morss (2000) sobre sonho e despertar, somos interpelados a reconhecer que "mundos de sonhos não são meramente ilusões. Em insistindo que o que está aí não é tudo o que existe, eles são asserções do espírito humano e politicamente difíceis de valorar". E prossegue afirmando que esses processos delicados "[...] fazem clamores momentâneos de que o mundo que conhecemos desde a infância não é o único imaginado" (Buck-Morss, 2000, p. 238). Mais uma vez, estamos frente à potência do fazer - e do não fazer.

Os agricultores pensavam no futuro e faziam planos sobre a vida, e eu também via adesões ao ideário comum das políticas públicas de desenvolvimento rural no Brasil. Se é surpreendente se deparar, em pesquisa, com esse desejo dos programas ou projetos de desenvolvimento já tantas vezes fracassados, há uma potencialidade na aspiração que escrutina as falhas e faz apropriações críticas, invertendo prioridades para satisfazer 
aquilo que almejam ${ }^{8}$. Não foram raras as vezes em que me vi envolvido em falas nas quais recorriam às mesmas receitas de mudança que temos testemunhado por décadas: mais presença do Estado, mais condições para funcionamento de mercados, mais crédito rural. Planos tantas vezes arruinados ou que geram benefícios modestos. Talvez fosse o modo que ao longo de muito tempo aprenderam a pensar um futuro melhor. Ainda assim, conjuntamente, outras orientações apareciam em falas e escapavam dessa mesmice do desenvolvimento.

Uma das razões está na crítica a esse desenvolvimento que, assim como a cena de teatro antes narrada, deslocando a realidade para uma espécie de "e se não fosse assim como temos vivido?", busca interromper este curso. O agricultor de Seara que antes me falava da sua história continuou:

Agroecologia é muito melhor porque é fácil ver que tem lugar para todos. A integração é excludente e as empresas exigem do agricultor a padronização total. A agroecologia funciona se há grupo, coletivo, cooperação.

Não foi a primeira nem a última vez que escutei sobre cooperação durante a pesquisa de campo. A insistência era expressiva e remetia à questão de construção de autonomia coletiva que estivesse tanto dissonante de um papel de cliente do Estado como do individualismo solipsista. Mas, mesmo quando Arnaldo, interlocutor em Novo Horizonte, apelava por fazer "um modelo diferente de desenvolvimento", eu sondava o quanto diferente seria, ou, ainda, em que medida ele próprio desenhava e imaginava se espelhar ou diferir dos modelos comuns e consagrados de desenvolvimento rural. ${ }^{9}$

Voltar o pensamento e olhar para si mesmo, exercício da reflexão do sujeito. O debate sobre subjetivação é longo e não é objetivo desta parte

${ }^{8}$ Wautier (2003) explora de modo pertinente e associado a esse processo as relações entre decomposição e recomposição do real por meio da categoria experiência presente na obra de François Dubet, autor ainda pouco discutido na sociologia brasileira.

9 Parte dos estudos etnográficos contemporâneos sobre projetos de desenvolvimento examina como deslocar o modo de pensar tais iniciativas intervencionistas para outra focada na maneira como os atores transmutam os sentidos dessas intervenções e de suas práticas políticas. Por razões de espaço não será possível examinar em detalhes. Para a discussão, ver Perrot (2008), Li (2007) e McMichael (2013). 
organizar uma revisão sistemática. Alguma reflexão sobre o tema impõe-se como necessária, pois não foram raras as vezes em que os entrevistados remeteram suas manifestações para problemas que circundam essa discussão. Especialmente, em ocasiões diversas, vi-me refletindo sobre como os agricultores buscavam organizar suas vidas em face dos acontecimentos e como isso implicava olhar, pensar e agir sobre si. Essa reflexividade refere-se, também, à própria constituição enquanto sujeito e, em particular, àquilo que antes expressei a respeito de circunscrever determinadas experiências de vida e torná-las únicas. Igualmente, enquanto coletivo, certa compreensão acerca de suas vidas moldava uma interpretação que se acumulava sobre os cursos de vida seguidos e mostrava determinadas possibilidades a respeito do que fazer no presente. Não se pode esquecer que, se em Dilthey a noção de experiência é verdadeiramente um trabalho consciente do indivíduo, em Benjamin não. Por essa razão, almejo destacar somente alguns aspectos adicionais deste debate.

Em Foucault (2006), percebemos a tematização do sujeito organizada como um voltar-se em direção a si mesmo e o autor alude justamente à metáfora do olho no espelho. Nessa volta em direção a si, a dobra é como um ato de produção de interioridade - efetivamente, a constituição do sujeito que se ocupa consigo próprio. A “consciência", escreve Butler (2017, p. 31) em parte inspirada em Foucault, "é o meio pelo qual o sujeito se torna objeto para si mesmo, refletindo sobre si mesmo, estabelecendo a si mesmo como refletivo e reflexivo." A reflexividade é tema que estrutura a emergência do sujeito, essa esfera interna, e que se estabelece no voltar-se sobre si (Butler, 2017).

É claro que sujeito, então, vem a ter profunda relação com processos de assujeitamento, razão que implica que para se tornar sujeito é preciso ser sujeitado, problema sublinhado pela autora. No entanto, sujeição também ocorre na relação consigo, na qual realizar um trabalho refletido e voluntário, parafraseando Foucault, é condição de ser e modificar-se 
(Foucault, 1998). ${ }^{10}$ E pode-se completar: "Não há, pois, um sujeito antes da relação consigo e do uso de si: o sujeito é essa relação, não os termos dela" (Agamben, 2017, p. 125) e incorpora os domínios do corpo e da interioridade. E qual ligação com a linguagem? Fala-se assumindo uma posição de sujeito - e o fato emblemático é que falar seja uma espécie de "força fraca": "[a] subjetividade, a consciência em que nossa cultura pensou ter encontrado o seu mais sólido fundamento, repousa sobre o que há de mais frágil e precário no mundo: o acontecimento da palavra" (Agamben, 2008, p. 126).

Em meio à pesquisa, também dialoguei com uma profissional de ciências agrárias encarregada, à época, de projetos de desenvolvimento regional junto às comunidades. Recordo de ter Ihe indagado sobre o papel ativo das pessoas quanto à autonomia - e, a essa altura da pesquisa, este tema já possuía muita recorrência - e ela afirmou ver na ação autônoma sentido quando vinculada ao lugar, aos valores compartilhados, mesmo que na Ecovida ocorra em Rede. Refletindo sobre o oeste catarinense, particularmente sobre projetos concretizados, disse que coisas positivas ocorreram quando projetos foram realizados amparados nas experiências coletivas no lugar.

Assim, pude observar que, para os interlocutores em campo, vários termos e práticas poderiam estar associados ao desenvolvimento, tais como autoconstrução, autonomia, conhecimentos com afinidades ao lugar, cooperação e solidarismo. O discurso do "mais do mesmo" tinha espaço expressivo (mais crédito, mais presença do Estado, mais apoio, mais extensionistas), todavia multiplicavam-se outros conteúdos que se evadiam desse registro, "teimavam" em não se deixar prender por ele.

\footnotetext{
${ }^{10}$ Seria oportuno também, para o leitor interessado, o ponto de vista de Foucault sobre a noção de experiência, particularmente como é apresentada por Foucault (1998). Para Brigstocke (2013), embora com pontos de partida distintos em Benjamin, é sugestivo perceber que Foucault via nos escritos do autor alemão sobre Baudelaire uma genealogia das artes de viver. Essa problematização é esclarecida por Foucault (1998, introdução) juntamente a opções metodológicas, incluindo a discussão sobre técnicas de si e a estética da existência, todas relacionadas à questão da subjetividade num prisma histórico-filosófico. Uma investigação mais demorada sobre a relação entre subjetivação e dobra se encontra em Deleuze (2005).
} 
Cabe insistir um pouco na noção de construção e no prefixo "auto", já que ela recupera a ideia de reflexividade. Um dos entrevistados, Antônio, falando de cooperação me fez ver a necessidade de distinguir a integração horizontal dos formatos verticalizados administrados pelas empresas ou cooperativas de porte maior, semelhante aos dilemas relatados em outros lugares e aqui antes descritos: "as cooperativas grandes não são nada democráticas, elas tiram a capacidade das pessoas de se autoconstruírem. Muitos agricultores não querem participar de nada" e seguiu:

eles vendem [como] independentes para mercados. Estes agricultores geralmente plantam grãos e vendem para cooperativas ou agroindústrias grandes, que vêm, compram, pesam, pagam. [Elas] acabam tirando a possibilidade da ação em conjunto.

Alguns estudos recentes sobre indivíduo e desenvolvimento têm buscado oferecer respostas para a relação entre regras, moralidades e mudança interior. Pandian (2008), em pesquisa na Índia e recuperando os escritos sobre subjetividade de Foucault, mostrou que, naquele contexto, trabalhar sobre si mesmo se apresenta como um telos moral, pois uma natureza (humana) imperfeita demanda esforço de constituição. Watanabe (2017), em pesquisa no oriente extremo, observou que a transformação do eu interior em projetos de intervenção, tornando-se pessoa-modelo, converte-se em meta mais importante que aquelas relativas a infraestruturas ou sistemas produtivos.

No caso de pesquisa aqui examinado, a autonomia é buscada pelos ecologistas porque envolve uma atitude de não depender de grandes empresas ou intermediários que são eventualmente inescrupulosos, porém ganha importância ao relacionar também os sistemas biofísicos do mundo rural (plantações, solo, animais e água). Já a autoconstrução se organiza em torno de reflexividade e subjetivação, implicando (re)constituição ao longo do tempo como num olhar para dentro, oportunizando que experiências do passado e o sentimento acerca do vivido no presente produzam mutações na maneira de ser. 


\section{Considerações finais}

Para finalizar estas reflexões, quero recuperar os pontos argumentados por Pandian (2008) e Watanabe (2017) brevemente mencionados. Ambos os casos apontam para o modo como as pessoas fazem uma hermenêutica de si e trabalham para mudar um eu interior. Se o fenômeno, mesmo em contextos culturais distintos, assinala a individualização e dificuldade de narrar ou transmitir experiência, essa parece ser uma indagação relevante e preocupação de nosso tempo. O caso de investigação de campo que procurei relatar neste artigo conduziu as conclusões para a importância dos aspectos colaborativos e sociais da experiência, traduzidos justamente pelo que é vivido em coletivo e manifesto na linguagem compartilhada. Entretanto, as preocupações com individualismo crescente e as críticas ao egoísmo eram presentes.

Ao dialogar com os entrevistados sobre processos de desenvolvimento, as respostas que ouvi dificilmente poderiam ser sintetizadas em uma visão sistêmica, ou seja, uma teorização completa. Em que pese, como mostrei, a matriz dos projetos de desenvolvimento amparados no "mais do mesmo" tivesse seu lugar e fosse significativa, outras narrativas marcavam presença. O entendimento mútuo em torno de um termo tão polissêmico (Rist, 2007) não foi fácil - palavra propensa a equívocos e cuja tradução eu procurava, com dificuldades, potencializar o entendimento dos atores. A partir desse contexto de pesquisa entre agricultores ecologistas, desenvolvimento apareceu como processo no qual ocorrem tanto a superação das formas de exploração como a autoconstrução subjetiva e colaborativa.

Ver, sentir, narrar e colaborar com iniciativas em agricultura ecológica oportunizava situações em que agricultores e agricultoras se percebiam construindo pontos de vista, experiências - e é de se sublinhar que o sofrimento vivido na agricultura havia desencadeado muitas das mudanças nas famílias. Experiências individuais e coletivas, presentes e passadas, conectavam linhas e sugeriam movimento, performadas tantos pelos aspectos cotidianos e perceptivos quanto no ato de narrar. Curiosamente, se Agamben 
(2011) afirmou que o ser humano precisa dizer "eu" para falar, tal movimento no âmbito do pensamento e da reflexão precisa considerar o que Butler (2017, p. 20) sublinha sobre olhar para si: “[...] o sujeito só pode referir à sua própria gênese assumindo uma perspectiva de terceira pessoa sobre si mesmo [...]". As abordagens mobilizadas neste artigo mostram-se profícuas para pesquisas que situam narrativas e memórias enquanto centrais dos processos vividos (outras possibilidades apareceriam com perspectivas não centradas na palavra). Um dos limites possíveis é relativo à etnografia: a opção por aprofundar biografias e relatos de vida, eventualmente em convivências mais longas com número reduzido de pessoas, pode gerar resultados bastante elucidativos.

Caberia, pela última vez, retomar o problema da autoconstrução, que se mostrou tão singular. Autoconstrução tem eficácia quando o espelho dilata o campo de visão para o interior e para o exterior, como em uma dialética do olhar (Buck-Morss, 2002), e com ele se enxergam as coisas como são e também como as pessoas gostariam que fossem. Assim como escreveu Adorno, Dawsey (2009) também destacou o modo como Benjamin se encanta com o fragmento, o infinitamente pequeno e, além disso, com o estilhaço do todo, assim como a oportunidade de se interromperem o curso dos acontecimentos, explodindo o tempo linear e invertendo narrativas dominantes. Quiçá exatamente dessa maneira possamos entender as experiências, narrativas e práticas desses agricultores ecológicos frente aos eventos do cotidiano e aos processos de desenvolvimento.

Guilherme F. W. Radomsky é Professor associado do departamento de Sociologia e do Programa de Pós-graduação em Sociologia da Universidade Federal do Rio Grande do Sul 


\section{Referências}

1. ADORNO, Theodor W. Introduction to Benjamin's Schriften. In: SMITH, Gary (Ed.). On Walter Benjamin: critical essays and recollections. Cambridge: MIT Press, 1988. p. 2-17.

2. ADORNO, Theodor W.; BENJAMIN, Walter. Correspondência, 1928-1940. 2. ed. rev. São Paulo: Unesp, 2012.

3. AGAMBEN, Giorgio. O uso dos corpos. São Paulo: Boitempo, 2017. (Homo Sacer IV, 2).

4. AGAMBEN, Giorgio. O homem sem conteúdo. Belo Horizonte: Autêntica, 2012.

5. AGAMBEN, Giorgio. O sacramento da linguagem: arqueologia do juramento. Belo Horizonte: Ed. UFMG, 2011. (Homo Sacer II, 3).

6. AGAMBEN, Giorgio. O que resta de Auschwitz. O arquivo e a testemunha. São Paulo: Boitempo, 2008. (Homo Sacer, III).

7. AGAMBEN, Giorgio. Infância e história: destruição da experiência e origem da história. Belo Horizonte: Ed. UFMG, 2005.

8. ASSIS, Renato; ROMEIRO, Ademar. Agroecologia e agricultura orgânica: controvérsias e tendências. Desenvolvimento e Meio Ambiente, n. 6, p. 67-80, jul./dez. 2002. http://dx.doi.org/10.5380/dma.v6i0.22129

9. BENJAMIN, Walter. Sobre a linguagem em geral e a linguagem do homem. In: GAGNEBIN, Jeanne Marie. (Org.). Escritos sobre mito e linguagem. São Paulo: Duas Cidades; Ed. 34, 2011. p. 49-73.

10. BENJAMIN, Walter. Passagens. Belo Horizonte: Ed. UFMG; São Paulo: Imprensa oficial do Estado de São Paulo, 2009.

11. BENJAMIN, Walter. On the mimetic faculty. In: JENNINGS, Michael; EILAND, Howard; SMITH, Gary (Ed.). Walter Benjamin: Selected writings. Cambridge: Belknap Press; Harvard University Press, 1999. (v. 2: 1927-1934). p. 720-722.

12. BENJAMIN, Walter. Program of the coming philosophy. In: SMITH, Gary. (Ed.). Benjamin: philosophy, history, aesthetics. Chicago: University of Chicago Press, 1989a. p. 1-13.

13. BENJAMIN, Walter. Sobre alguns temas em Baudelaire. In: BENJAMIN, Walter. Charles Baudelaire: um lírico no auge do capitalismo. São Paulo: Brasiliense, 1989b. (Obras Escolhidas, v. 3). p. 103-149.

14. BENJAMIN, Walter. O narrador. Considerações sobre a obra de Nikolai Leskov. In: BENJAMIN, Walter. Magia e técnica, arte e literatura: ensaios sobre literatura e história da cultura. São Paulo: Brasiliense. 4. ed. 1985a. (Obras escolhidas, v.1). p. 197-221.

15. BENJAMIN, Walter. Experiência e pobreza. In: BENJAMIN, Walter. Magia e técnica, arte e literatura: ensaios sobre literatura e história da cultura. São Paulo: Brasiliense. 4. ed. 1985b. (Obras escolhidas, v. 1). p. 114-119. 
16. BENVEGNÚ, Vinicius; RADOMSKY, Guilherme W. Entre o sucesso e o fracasso: desenvolvimento, sementes crioulas e transgênicas. Novos Cadernos NAEA, v. 23, n. 1, p. 171-193, 2020. http://dx.doi.org/10.5801/ncn.v23i1.6060

17. BRIGSTOCKE, Julian. Artistic parrhesia and the genealogy of ethics in Foucault and Benjamin. Theory, Culture \& Society, v. 30, n. 1, p. 57-78, 2013. https://doi. org/10.1177\%2F0263276412450467

18. BRUNER, Edward. Experience and its expressions. In: TURNER, Victor; BRUNER, Edward (Ed.). The anthropology of experience. Urbana: University of Illinois Press, 1986. p. 3-30.

19. BUCK-MORSS, Susan. Dialética do olhar: Walter Benjamin e o projeto das passagens. Belo Horizonte: Ed. UFMG; Chapecó: Argos, 2002.

20. BUCK-MORSS, Susan. Dreamworld and catastrophe: the passing of mass utopia in East and West. Cambridge: MIT Press, 2000.

21. BUTLER, Judith. A vida psíquica do poder. Teorias da sujeição. Belo Horizonte: Autêntica, 2017.

22. DAWSEY, John. Tonantzin: Victor Turner, Walter Benjamin e a Antropologia da experiência. Sociologia \& Antropologia, v. 3, n. 6, p. 379-410, 2013. http://dx.doi.org/10.1590/2238-38752013v362

23. DAWSEY, John. Por uma antropologia benjaminiana: repensando paradigmas do teatro dramático. Mana, v. 15, n. 2, p. 349-376, 2009. http://dx.doi. org/10.1590/S0104-93132009000200002

24. DAWSEY, John. O teatro em Aparecida: a santa e o lobisomem. Mana, v. 12, n. 1, p. 135-149, 2006. http://dx.doi.org/10.1590/S0104-93132006000100005

25. DELEUZE, Gilles. Foucault. São Paulo: Brasiliense, 2005.

26. FONSECA, Maria F. A institucionalização dos mercados de orgânicos no mundo e no Brasil: uma interpretação. 2005. Tese (Doutorado) - CPDA, Universidade Federal Rural do Rio de Janeiro, Rio de Janeiro, 2005.

27. FOUCAULT, Michel. O governo de si e dos outros: curso dado no Collège de France (1982-1983). São Paulo: Martins Fontes, 2010.

28. FOUCAULT, Michel. A hermenêutica do sujeito: curso dado no Collège de France (1981-1982). 2. ed. São Paulo: Martins Fontes, 2006.

29. FOUCAULT, Michel. História da sexualidade. Rio de Janeiro: Graal, 1998. (v. 2: o uso dos prazeres).

30. GAGNEBIN, Jeanne Marie. Prefácio. Walter Benjamin ou a história aberta. In: BENJAMIN, Walter. Magia e técnica, arte e literatura: ensaios sobre literatura e história da cultura. 4. ed. São Paulo: Brasiliense. Tradução de Sergio Rouanet. 1985b. (Obras escolhidas, v. 1). p. 7-19.

31. GOODMAN, David; GOODMAN, Michael. Localism, livelihoods and the 'post-organic': changing perspectives on alternative food networks in the United States. In: MAYE, Damian; HOLLOWAY, Lewis; KNEAFSEY, Moya (Ed.). Alternative food geographies: representation and practice. Amsterdã: Elsevier, 2007. p. 23-38. 
32. HARTMANN, Luciana. Performance e experiência nas narrativas orais da fronteira entre Argentina, Brasil e Uruguai. Horizontes Antropológicos, v. 11, n. 24, p. 125-153, 2005. http://dx.doi.org/10.1590/S0104-71832005000200007

33. JAY, Martin. Songs of experience. Modern American and European variations on a universal theme. Berkeley; Londres: University of California Press, 2005.

34. KANG, Jaeho. O espetáculo da modernidade: a crítica da cultura de Walter Benjamin. Novos Estudos CEBRAP, v. 84, p. 215-233, 2009. http://dx.doi. org/10.1590/S0101-33002009000200012

35. LI, Tania M. The will to improve: governmentality, development and practice of politics. Durham: Duke University Press, 2007.

36. LUCION, Jéssica. A institucionalização da produção orgânica no Brasil Reflexões a partir da certificação participativa no âmbito da Rede de Agroecologia Ecovida (RS). Contraponto, v. 3, p. 131-145, 2016.

37. McMICHAEL, Philip. Changing the subject of development. In: McMICHAEL, Philip. (Ed.). Contesting development: critical struggles for social change. Nova York; Londres: Routledge, 2013. p. 1-13.

38. NIEDERLE, Paulo; ALMEIDA, Luciano de; VEZZANI, Fabiane (Org.). Agroecologia: práticas, mercados e políticas para uma nova agricultura. Curitiba: Kairós, 2013.

39. PANDIAN, Anand. Devoted to development: moral progress, ethical work, and divine favor in south India. Anthropological Theory, v. 8, n. 2, p. 159-179, 2008. https://doi.org/10.1177\%2F1463499608090789

40. PERROT, Dominique. Quem impede o desenvolvimento "circular"? (Desenvolvimento e povos autóctones: paradoxos e alternativas). Cadernos de campo, São Paulo, n. 17, p. 219-232, 2008. https://doi.org/10.11606/issn.23169133.v17i17p219-232

41. RADOMSKY, Guilherme W. O poder do selo: imaginários ecológicos, formas de certificação e regimes de propriedade intelectual no sistema agroalimentar. Porto Alegre: Ed. da UFRGS, 2015.

42. RIST, Gilbert. Development as a buzzword. Development in practice, v. 17, p. 485-491, 2007. https://doi.org/10.1080/09614520701469328

43. ROVER, Oscar. Agroecologia, mercado e inovação social: o caso da Rede Ecovida de Agroecologia. Ciências Sociais Unisinos, n. 47, p. 56-63, 2011. https://doi.org/10.4013/1044

44. SILVEIRA, Suzana. Rede Ecovida de Agroecologia: uma inovação estratégica para o desenvolvimento territorial sustentável na zona costeira catarinense? Interthesis, v. 10, n. 2, p. 181-213, 2013. https://doi.org/10.5007/18071384.2013v10n2p181

45. TURNER, Victor. On the edge of the bush. Anthropology as experience. Tucson: University of Arizona Press, 1985. 
46. TURNER, Victor. Dewey, Dilthey, and drama: an essay in the anthropology of experience. In: TURNER, Victor; BRUNER, Edward (Ed.) The anthropology of experience. Urbana: University of Illinois Press, 1986. p. 33-44.

47. WATANABE, Chika. Development as pedagogy: On becoming good models in Japan and Myanmar. American Ethnologist, v. 44, n. 4, p. 591-602, 2017. https://doi.org/10.1111/amet.12559

48. WAUTIER, Anne M. Por uma sociologia da experiência. Uma leitura contemporânea: François Dubet. Sociologias, Porto Alegre, v. 5, n. 9, p. 174-214, jan./jun. 2003. https://doi.org/10.1590/S1517-45222003000100007 